\title{
Top-down Control over the Processing of Task-irrelevant Rule Violation: Evidence from Visual Mismatch Negativity
}

\author{
産業技術総合研究所 \\ 木村 元洋 \\ 産業技術総合研究所 \\ 武田裕司
}

\section{Top-down Control over the Processing of Task-irrelevant Rule Violation: Evidence from Visual Mismatch Negativity}

\author{
Motohiro KIMURA \\ National Institute of Advanced Industrial Science and Technology \\ Yuji TAKEDA \\ National Institute of Advanced Industrial Science and Technology
}

\begin{abstract}
An event-related brain potential component called visual mismatch negativity (MMN) reflects the automatic processing of rule-violating events embedded in a visual stimulus sequence. To investigate whether or not the processing of rule-violating events in a task-irrelevant stimulus sequence can be affected by top-down control, we examined the effects of the participant's voluntary action on visual MMN with a dual-task design. As a primary task, the participants were required to detect a sudden size-change of a central fixation point. As a secondary task, they were required to press one button frequently (about 90\%) and another button infrequently $(10 \%)$ in random order, which produced a task-irrelevant stimulus sequence at surrounding locations. Frequently-performed button presses triggered rule-conforming stimuli $(81 \%)$, but occasionally rule-violating stimuli ( $9 \%$, externally-generated rule violation). In contrast, infrequently-performed button presses triggered rule-violating stimuli (9\%, self-generated rule violation), but occasionally rule-conforming stimuli (1\%). Visual MMN was elicited by externally-generated rule violation, but not by self-generated rule violation. This result indicates that the processing of rule-violating events in a task-irrelevant stimulus sequence can be modulated by top-down control.
\end{abstract}

2015.3.10 受稿, 2015.6.3 受理, 2016.1.28 J-STAGE 早期公開, doi: 10.5674/jjppp.1504si

連絡者及び連絡先：テ305-8566 茨城県つくば市東1-1-1 産総研中央第六 木村元洋

E-mail: m.kimura@aist.go.jp 
Key words : rule violation, voluntary action, top-down control, event-related brain potential (ERP), visual mismatch negativity (MMN)

【要 約】視覚ミスマッチ陰性電位とよばれる事象関連脳電位成分は, 視覚刺激系列に内在するルール妨害事象 の自動的な処理を反映する。課題に関連しない刺激系列に内在するルール妨害事象の処理がトップダウン制御に よって影響されるか否かを調べるため, 我々は実験参加者の随意的行為が視覚ミスマッチ陰性電位に及ぼす影響 を, 二重課題デザインを用いて検討した。一次課題として, 実験参加者は中心凝視点の突然のサイズ变化を検出 することを求められた。二次課題として，一方のボタンを高頻度 (およそ90\%), 他方のボ夕ンを低頻度 $(10 \%)$ で, ランダム順に押すことを求められた。これらのボタン押しにより, 周辺位置に課題非関連の刺激系列が作り 出された。高頻度で行われたボタン押しはルール適合刺激を生じさせたが $(81 \%)$, 時々, ルール妨害刺激を生じ させた $(9 \%$, 外部によって作り出されたルール妨害事象)。一方, 低頻度で行われたボタン押しはルール妨害刺 激を生じさせたが ( $9 \%$, 自分が作り出したルール妨害事象), 時々, ルール適合刺激を生じさせた (1\%)。視覚 ミスマッチ陰性電位は, 外部によって作り出されたルール妨害事象によって惹起したが, 自分が作り出したルー ル妨害事象によっては惹起しなかった。この結果は, 課題に関連しない刺激系列に内在するルール妨害事象の処 理が，トップダウン制御によって変容しうることを示している。

\section{Automatic processing of rule violation indexed by visual mismatch negativity}

The external environment contains many sensory events. However, the brain cannot analyze all of these events in depth due to its limited capacity. Therefore, an essential task of the brain is to achieve the effective selection of biologically significant sensory events, even when they are unrelated to the ongoing task. Event-related brain potential (ERP) studies have provided converging evidence that the brain is well organized to select novel or salient events that violate regular aspects of the sensory environment. Such selective processing of novel or salient events is the fundamental function of attention (Näätänen, 1992; Schröger, 1997).

ERP studies have shown that, when sequential rules embedded in a visual stimulus sequence are violated, a negative-going ERP component called visual mismatch negativity (MMN) is elicited at around 100-400 ms after event onset with an occipitotemporal scalp distribution (for reviews, see Czigler, 2007; Kimura, 2012; Kimura et al., 2011; Stefanics et al., 2014; Winkler \& Czigler, 2012). Visual MMN has been observed in response to repetition-rule-violating stimuli (i.e., deviant stimuli) that are occasionally inserted in a sequence of repetition-rule-conforming stimuli (i.e., standard stimuli in an oddball sequence) (e.g., Astikainen et al., 2008; Czigler et al., 2002; Kimura et al., 2009; Kimura \& Takeda, 2013), as well as change-rule-violating stimuli (i.e., irregular stimuli) that are occasionally inserted in a more complex sequence of change-rule-conforming stimuli (i.e., regular stimuli) (Czigler et al., 2006; Kimura \& Takeda, in press; Stefanics et al., 2011). Importantly, these findings have been obtained under experimental conditions in which the participant's ongoing task is unrelated to the stimulus sequence and the participants are instructed to not direct attention to the stimulus sequence. Therefore, it is widely accepted that visual MMN reflects the automatic processing of rule-violating events.

Top-down control of the processing of rule violation Previous visual MMN studies have addressed whether the automatic processing of rule-violating events are determined in a bottom-up (i.e., stimulus-driven) manner, or can be modulated by top-down control; this is similar to the well-known debate on the "automatic attentional capture" (Theeuwes, 1991, 1992; Yantis \& Jonides, 1984) versus "contingent attentional capture" hypothesis (Folk et al., 1992, 1994) regarding the "pop-out" phenomenon in a visual search task. Most visual MMN studies have suggested 
that the processing of rule-violating events is determined in a stimulus-driven manner. The main findings come from studies that investigated the effects of task load on visual MMN (Heslenfeld, 2003; Kimura \& Takeda, 2013; Kremláček et al., 2013; PazoAlvarez et al., 2004). For example, Kimura and Takeda (2013) presented a visual stimulus sequence consisting of rule-conforming and rule-violating stimuli at surrounding visual fields, while the participant performed a size-change detection task regarding a continuously-presented fixation point at a central visual field. Task load was manipulated by varying the magnitude of the size-change. They found that manipulation of the task load does not significantly influence the elicitation of visual MMN (for similar results, see Heslenfeld, 2003; Kremláček et al., 2013; Pazo-Alvarez et al., 2004). This result supports the notion that the processing of rule-violating events operates in a stimulus-driven manner and is insensitive to top-down control.

However, Kimura and Takeda (2014) recently provided new evidence for the top-down modulation of visual MMN, where they investigated the effects of the participant's voluntary action on visual MMN. They required the participants to press one button frequently and another button infrequently in random order, which produced a visual stimulus sequence consisting of rule-conforming and rule-violating stimuli at a central visual field. Frequently-performed button presses triggered rule-conforming stimuli, but occasionally rule-violating stimuli (i.e., externallygenerated rule violation, the occurrence of which cannot be expected in advance). In contrast, infrequently-performed button presses triggered ruleviolating stimuli (i.e., self-generated rule violation, the occurrence of which can be expected in advance), but occasionally rule-conforming stimuli. The results showed that visual MMN was elicited by rule-violating stimuli triggered by frequently-performed button presses, whereas it was not elicited by physically the same rule-violating stimuli triggered by infrequentlyperformed button presses. This result suggests that, although the processing of rule-violating events basically operates in a stimulus-driven manner, it can be affected by top-down control.

\section{Present study}

The action-induced modulation of visual MMN sheds new light on top-down influences on the processing of rule-violating events. The present study further investigated whether or not the processing of ruleviolating events can be affected by voluntary action, even when the rule-violating events are embedded in a task-irrelevant stimulus sequence. Unlike typical visual MMN studies in which a stimulus sequence was task-irrelevant and the participants were instructed to not direct attention to the stimulus sequence (see e.g., Czigler et al., 2002, 2006; Kimura \& Takeda, 2013, in press), Kimura and Takeda (2014) instructed the participants to closely observe a stimulus sequence produced by their own button presses. Thus, it is plausible that the participants actively directed their attention to the stimulus sequence. At present, it is unclear whether or not voluntary action also modulates the processing of rule-violating events, even when the rule-violating events are embedded in a task-irrelevant stimulus sequence and the participants are instructed to not direct attention to the stimulus sequence.

To address this issue, we examined the effects of voluntary action on visual MMN with a dual-task design. As a primary task, the participants were required to detect a sudden change in the size of a continuously-presented fixation point at a central visual field. This task was the same as that which has been used in typical visual MMN studies (e.g., Czigler et al., 2002, 2006; Kimura \& Takeda, 2013, in press). As a secondary task, the participants were required to press one button frequently and another button infrequently in random order. The button presses produce a visual stimulus sequence at the surrounding visual fields, but the participants were instructed to not direct attention to the stimulus sequence. Frequently-performed button presses triggered rule-conforming stimuli, but occasionally triggered rule-violating stimuli (i.e., externally- 
generated rule violation). In contrast, infrequentlyperformed button presses triggered rule-violating stimuli (i.e., self-generated rule violation), but occasionally triggered rule-conforming stimuli. This task was the same as that used in our previous study (Kimura \& Takeda, 2014), except that a visual stimulus sequence was produced at the surrounding visual fields and was made task-irrelevant for the participants. If the processing of rule-violating events embedded in a task-irrelevant stimulus sequence is affected by voluntary action, then visual MMN should be elicited by rule-violating stimuli triggered by frequently-performed button presses, but no (or at least reduced) visual MMN should be elicited by ruleviolating stimuli triggered by infrequently-performed button presses. In contrast, if it is insensitive to topdown control, then visual MMN should be similarly elicited by these two types of rule-violating stimuli.

\section{Methods}

\section{Participants}

Twenty-two young adults (4 women, 18 men; age range $=19-31$ years, mean $=22.8$ years $)$ participated in this experiment. Twenty-one participants were right-handed and one was left-handed. All participants had normal or corrected-to-normal vision and were free of neurological or psychiatric disorders. Written informed consent was obtained from each participant after the nature of the study had been explained. The experiment was approved by the Safety and Ethics committee of the National Institute of Advanced Industrial Science and Technology (AIST).

\section{Stimuli and Procedure}

The experiment was controlled by programs written in MATLAB (Mathworks) with the Psychophysics Toolbox (Brainard, 1997; Pelli, 1997) installed on a computer (Apple, MacBook Pro 8.2; AMD, Radeon HD 6770M). All stimuli were presented on a 17 -inch cathode ray tube display (Sony, Trinitron Multiscan G220). Figure 1A shows an example of the stimulus display that consisted of a central fixation point and a surrounding bar array. The fixation point was a gray circle (luminance of $14.5 \mathrm{~cd} / \mathrm{m}^{2}$ and visual angle of $1.1^{\circ}$ from a viewing distance of $70 \mathrm{~cm}$ ). The bar array consisted of eight gray bars (luminance of $14.5 \mathrm{~cd} / \mathrm{m}^{2}$ and visual angle of $3.0^{\circ} \times 0.4^{\circ}$, respectively) at eight surrounding locations $\left(3.3^{\circ}\right.$ upper, lower, left, and right and $4.6^{\circ}$ upper-left, upper-right, lower-left, and lower-right from the center of the fixation circle to the center of each bar, respectively) against a black background. Eight bar arrays that differed with respect to orientation were used $\left(0.0^{\circ}, 22.5^{\circ}, 45.0^{\circ}, 67.5^{\circ}, 90.0^{\circ}\right.$, $112.5^{\circ}, 135.0^{\circ}$, and $157.5^{\circ}$ from the horizontal to the right, steps of $22.5^{\circ}$ ) (see Figure 1B).

The participants' primary task was to detect a sudden change in the size of a fixation circle. A fixation circle was continuously presented at the center of the display throughout a block. From time to time, the size of the fixation circle suddenly became smaller, from $1.1^{\circ}$ to $0.7^{\circ}$ (Figure 1C). The frequency of this size-change was 1.5-3.0 times/min and the exposure duration of the size-changed fixation circle was fixed at $100 \mathrm{~ms}$. The timing of the size-change was independent of the presentation of the surrounding bar array, with the limitation that the size-change did not occur within the 10-s interval at the beginning of each block and at least a 5-s interval was inserted between a size-change and the subsequent size-change. In each block, the participants were required to respond as quickly and accurately as possible when the fixation circle became smaller. Since the participants' hands were assigned to the secondary task (see below), we recorded the participants' voice response ("yes": "ha-i" in Japanese) with a microphone (Elecom, MSSTM88SV) and a microphone mixer (Sony, MX-50).

The participants' secondary task was to press the left and right buttons of a gamepad (Logitech, RumblePad 2). The participants were required to frequently press one (e.g., left) button with the index finger of one (left) hand and infrequently press another (right) button with the index finger of the other (right) hand. There were five constraints regarding the button press: (1) the interval between 
A

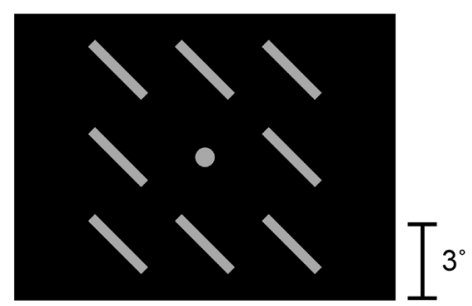

C

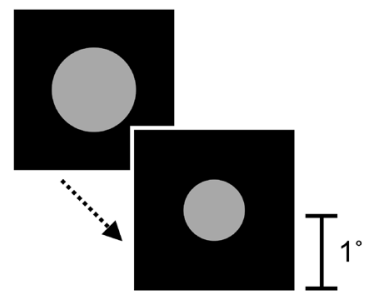

B

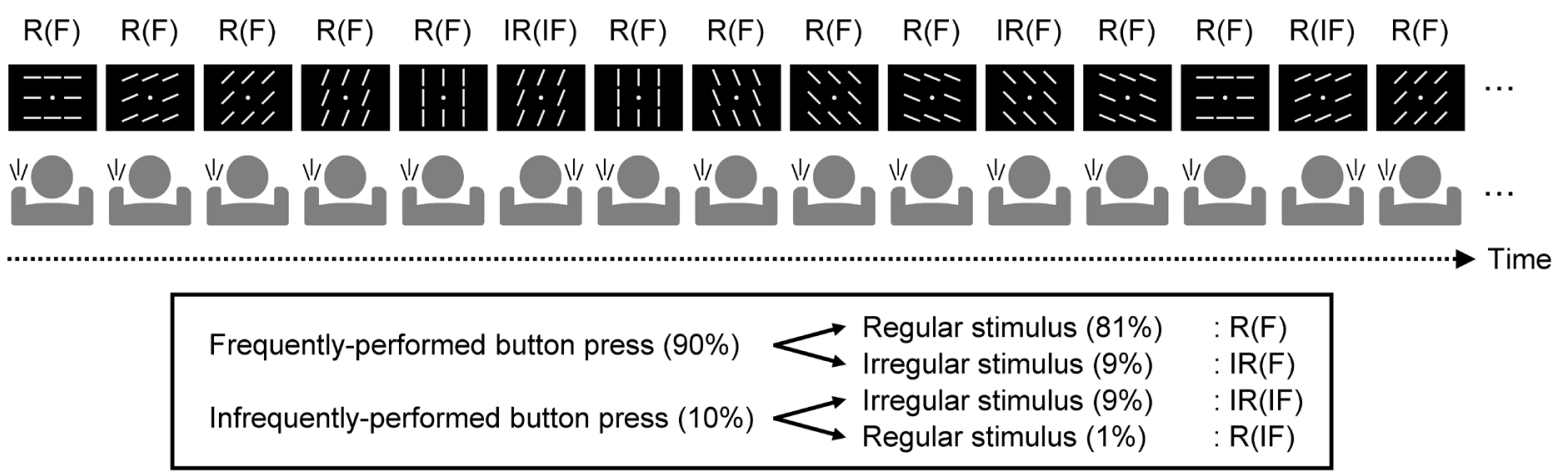

Figure 1. (A) An example of the stimulus display showing a central fixation circle and a surrounding bar array. (B) A schematic illustration of the stimuli and procedure. As a primary task, the participants performed a sizechange detection task regarding a continuously-presented central fixation circle. As a secondary task, the participants pressed one button frequently and another button infrequently in random order, which produced a task-irrelevant visual stimulus sequence consisting of regular and irregular stimuli (i.e., surrounding bar arrays).

(C) Change in the size of the central fixation circle (i.e., target for the primary task).

the current and preceding button presses had to be within a range of $500-800 \mathrm{~ms}$, (2) the percentages of frequently-performed and infrequently-performed button presses had to be about $90 \%$ and $10 \%$, respectively, (3) an infrequently-performed button press could not be made twice (or more) in a row, (4) the two types of button presses had to be made in random order, and (5) the two types of button presses should not be made according to a fixed sequential pattern (e.g., every tenth action was an infrequentlyperformed button press). Each button press triggered the surrounding bar array, with a constant delay interval (i.e., from button press to stimulus onset) of $50 \mathrm{~ms}$. The bar arrays were presented for a fixed duration of $250 \mathrm{~ms}$.

As shown in Figure 1B, the participants' button presses produced a stimulus sequence consisting of regular and irregular stimuli. Eight bars that differed in orientation were regularly presented in a rotating manner with a $22.5^{\circ}$ angular difference (regular stimuli), and occasionally reversed (irregular stimuli). Frequently-performed button presses ("F") triggered regular stimuli (“R”) [ "R (F)" stimulus, 81\%], but occasionally triggered irregular stimuli ("IR") ["IR (F)" stimulus, 9\%]. In contrast, infrequentlyperformed button presses ( $I F$ ") triggered irregular stimuli ["IR (IF)" stimulus, 9\%] but occasionally triggered regular stimuli [“R(IF)" stimulus, 1\%]. Note that we used a stimulus sequence consisting of regular and irregular stimuli rather than the typical oddball sequence consisting of standard and deviant stimuli, since the comparison between standard and deviant ERPs is not optimal for extracting visual MMN without the contamination of a refractorinessrelated N1 effect (for details, see Kimura et al., 2009; Kimura \& Takeda, in press). 
The experiment consisted of 20 blocks. Each block consisted of 200 button presses, resulting in 200 bar arrays. Half of the participants (11 participants) pressed the left button frequently and the right button infrequently in the first 10 blocks, and this was reversed in the last 10 blocks. For the other participants (11 participants), the order was reversed. In the 10 blocks where the participants pressed the left button frequently and the right button infrequently, the sequences were comprised of regular counterclockwise rotations. In the 10 blocks in which the participant pressed the right button frequently and the left button infrequently, the sequences were comprised of regular clockwise rotations. Through these 20 blocks, the physical properties of the regular and irregular stimuli were the same, which allowed us to evaluate visual MMN without contamination due to the effects of physical differences in the eliciting stimuli. Note also that each block took about $2 \mathrm{~min}$, and therefore the size-change of a fixation circle occurred about 3-5 times in each block.

In all blocks, the participants performed the primary and secondary tasks while seated on a reclining chair in a sound-attenuated and electricallyshielded, dimly lit room. Before the start of the experiment, the participants were instructed to (1) focus on the fixation circle, (2) respond by voice as quickly and accurately as possible when the fixation circle became smaller, (3) make button presses as accurately as possible, (4) ignore surrounding bar arrays, and (5) minimize any eye movement and blinking during each block. After the end of each block, the participants were given feedback about the pace of button presses and the ratio of frequentlyperformed and infrequently-performed button presses in the corresponding block.

\section{Recordings}

The electroencephalogram (EEG) was recorded with a digital amplifier (Nihon-Kohden, Neurofax EEG1100) and silver-silver chloride electrodes placed at 26 scalp sites (Fp1, Fp2, F7, F3, Fz, F4, F8, FCz, T7, $\mathrm{C} 3, \mathrm{Cz}, \mathrm{C} 4, \mathrm{~T} 8, \mathrm{P} 7, \mathrm{P} 3, \mathrm{Pz}, \mathrm{P} 4, \mathrm{P} 8, \mathrm{PO} 7, \mathrm{PO}, \mathrm{POz}$,
PO4, PO8, O1, Oz, and $\mathrm{O} 2$ according to the extended International 10-20 System). All electrodes were referenced to the nose tip. To monitor blinks and eye movements, vertical and horizontal electrooculograms (EOGs) were also recorded with two electrodes above and below the right eye and two electrodes at the right and left outer canthi of the eyes, respectively. The impedance of all electrodes was kept below $10 \mathrm{k} \Omega$. The EEG and EOG signals were digitized at a sampling rate of $1000 \mathrm{~Hz}$ and bandpass-filtered at $1.5-30 \mathrm{~Hz}$ with a finite impulse response (FIR) filter implemented in EEGLAB (Delorme \& Makeig, 2004) (3625-point Kaiser-windowed filter).

\section{Data analysis}

Behavioral performance. Behavioral performance for the primary task was measured in terms of hit rate (\%). Voice responses were scored as a hit if they were performed within 200-1200 ms after the onset of the size-change of the fixation circle.

Behavioral performance for the secondary task was measured in terms of (1) the percentage of frequently-performed and infrequently-performed button presses, (2) the percentage of correct button presses (i.e., within the range of 500-800 $\mathrm{ms}$ from the preceding button press) for frequently-performed and infrequently-performed button presses, respectively, and (3) the mean time interval between correct button presses and the preceding button presses for frequently-performed and infrequently-performed button presses, respectively. To confirm that the percentage of correct button presses and the mean time intervals were not significantly different between frequently-performed and infrequently-performed button presses, the measured values were subjected to two-tailed paired $t$-tests. The effect sizes are presented as $d$-values.

ERPs. The EEG and EOG signals time-locked to stimulus onset were averaged for the R $(F), I R(F)$, and IR (IF) stimuli; the R (IF) stimuli were excluded from the analyses, due to the extremely small averaging number (i.e., $1 \%$ of trials) as well as the low relevance to the purpose of the present study. Here, only stimuli 
that were triggered by correct button presses were averaged. Averaging epochs were $600 \mathrm{~ms}$, including a 100 -ms pre-stimulus baseline. In the averaging procedure, (1) the first eight epochs in each block, (2) epochs during which the signal changes exceeded $\pm 80 \mu \mathrm{V}$ on any of the electrodes, (3) two epochs that were preceded by epochs in which IR (F) or IR(IF) stimuli were presented, and (4) epochs during which the size of the fixation circle changed and the three subsequent epochs, were excluded from averaging.

Following the analysis in Kimura and Takeda (2014), to extract visual MMN in response to IR (F) and IR (IF) stimuli, grand-average IR (F) -minus-R (F) and IR (IF)-minus- $R(F)$ difference waves were calculated. The mean amplitudes of the difference waves were then calculated for left and right occipitotemporal clusters (i.e., the PO7 and P7 electrodes for the left cluster and the PO8 and P8 electrodes for the right cluster) within a 50-ms time window (270$320 \mathrm{~ms}$ ). This time window was determined by visually inspecting the grand-average difference waves and by considering the typical latency range of visual $\mathrm{MMN}$ in response to irregular stimuli in a complex stimulus sequence (Czigler et al., 2006; Kimura \& Takeda, in press; Stefanics et al., 2011).

To test the significant elicitation of visual MMN, the mean amplitudes of the IR (F)-minus-R (F) and IR (IF) -minus-R (F) difference waves at the left and right clusters within the $270-320 \mathrm{~ms}$ time window were compared to zero with one-tailed $t$-tests. The effect sizes are presented as $d$-values. Next, to directly compare visual MMN in the IR $(\mathrm{F})$-minus- $\mathrm{R}(\mathrm{F})$ and IR (IF)-minus-R (F) difference waves, the mean amplitudes of difference waves were subjected to repeated-measures ANOVAs with two factors: 2 Difference waves [IR (F)-minus-R (F) vs. IR (IF)minus-R (F) ] and 2 Clusters (Left vs. Right). Effect sizes were calculated as partial eta squared $\left(\eta^{2}\right)$. Posthoc comparisons involved two-tailed paired $t$-tests with the Bonferroni correction.

\section{Results}

\section{Behavioral performance}

For the primary task, the hit rate was $90.8 \%(S E=$ 2.3). For the secondary task, the percentage of frequently-performed and infrequently-performed button presses was $90.2 \%(S E=0.1)$ and $9.8 \%(0.1)$, respectively. $96.7 \%(S E=0.8)$ of the frequentlyperformed button presses and $94.0 \%$ (2.4) of the infrequently-performed button presses were correct button presses (i.e., within the range of $500-800 \mathrm{~ms}$ from the preceding button press). A two-tailed paired $t$-test showed no significant effect $(t=1.58)$. The mean time intervals between correct button presses and the preceding button presses for frequently-performed and infrequently-performed button presses were $602.6 \mathrm{~ms}(S E=7.4)$ and $599.9 \mathrm{~ms}$ (7.3), respectively. A two-tailed paired $t$-test showed no significant effect $(t=1.30)$.

\section{ERPs}

The number of $\mathrm{R}(\mathrm{F})$, IR (F), and IR (IF) stimuli that were produced by correct button presses was 3139.0 $(S E=26.0), 349.5$ (3.1), and 329.6 (9.0), respectively. Based on the aforementioned exclusion criteria for ERP averaging, the number of averaged epochs was $1639.5(S E=38.1), 235.8$ (5.1), and 218.0 (6.8), respectively.

Figure 2A shows the grand-average ERPs elicited by the IR $(F)$ and $R(F)$ stimuli and the IR $(F)$ minus- $R(F)$ difference wave. In the difference wave, a posterior negative deflection that peaked at around $300 \mathrm{~ms}$ after stimulus onset was observed. Figure 2B shows topographical maps of the difference wave within the 270-320 ms time window. The posterior negative deflection had a bilateral occipito-temporal scalp distribution. Figure 2B also shows the grandaverage mean amplitudes of the difference wave within the 270-320 ms time windows at the left and right occipito-temporal clusters. The mean amplitudes were $-0.46 \mu \mathrm{V}(S E=0.09)$ for the left cluster and $-0.42 \mu \mathrm{V}(0.10)$ for the right cluster. One-tailed $t$-tests revealed the significance of negative deflection 
A
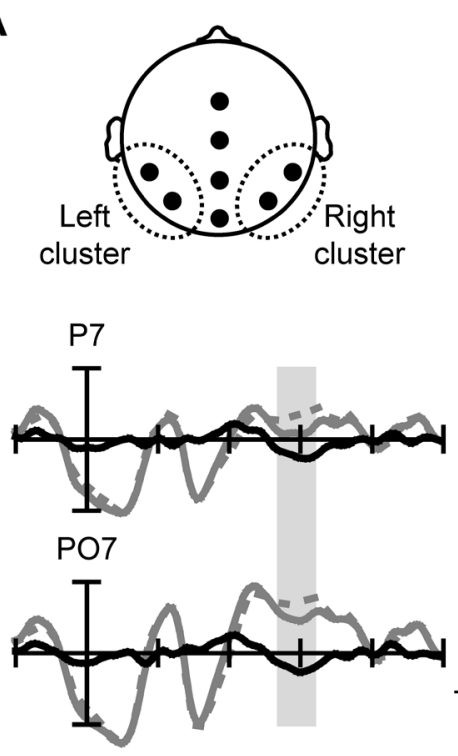

MMN range

$(270-320 \mathrm{~ms})$
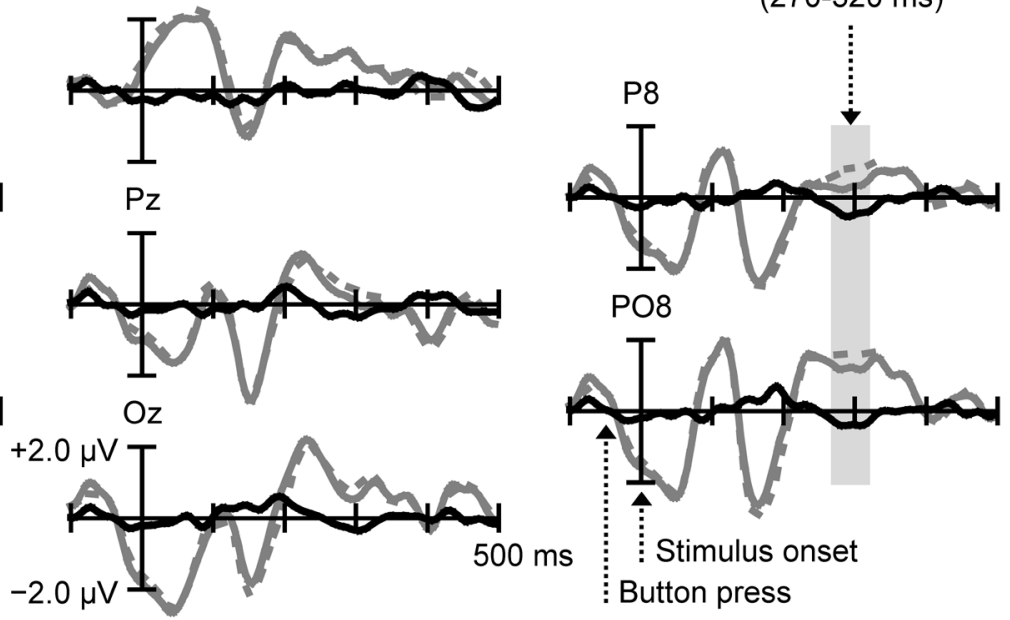

\section{- $I R(F) \quad \ldots=R(F)$ - $I R(F)-$ minus- $R(F)$ difference}

B

MMN range (270-320 ms)
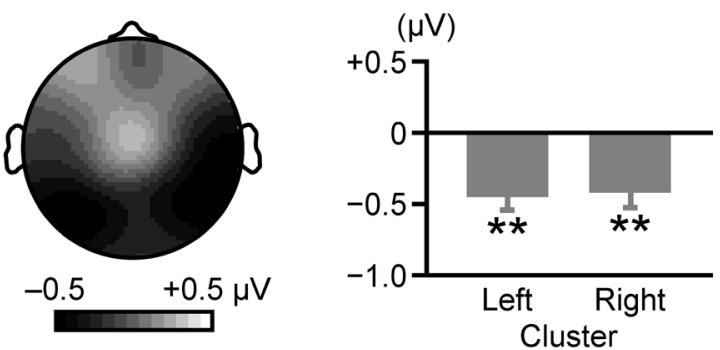

Figure 2. (A) Grand-average ERPs elicited by $I R(F)$ and $R(F)$ stimuli and the IR $(F)$-minus-R $(F)$ difference wave at eight electrode locations. (B) Topographical map and mean amplitudes (left cluster from the PO7 and P7 electrodes; right cluster from the PO8 and P8 electrodes) of the IR (F)-minus-R (F) difference wave within the 270-320 ms time window. Error bars indicate $S E$. Asterisks indicate the significance of negative deflection by one-tailed $t$-test $(* *: p<.001)$.

for both the left $(t(21)=5.01, p<.001, d=1.07)$ and right clusters $(t(21)=4.10, p<.001, d=0.87)$.

Figure $3 \mathrm{~A}$ shows the grand-average ERPs elicited by the IR (IF) and $R(F)$ stimuli and the IR (IF) -minus-R (F) difference wave. In the difference wave, no clear negative deflection was observed. Figure 3B shows topographical maps of the difference wave within the 270-320 ms time window. No sign of posterior negative deflection was observed. Figure 3B also shows the grand-average mean amplitudes of the difference wave within the 270-320 ms time window at the left and right occipito-temporal clusters. The mean amplitudes were $-0.08 \mu \mathrm{V}(S E=0.15)$ for the left cluster and $0.18 \mu \mathrm{V}(0.14)$ for the right cluster. One-tailed $t$-tests showed no significant effect for both the left $(t=0.53)$ and right clusters $(t=-1.28)$.

Two-way ANOVAs (2 Difference waves $\times 2$ Clusters) performed on the mean amplitudes of the 
A
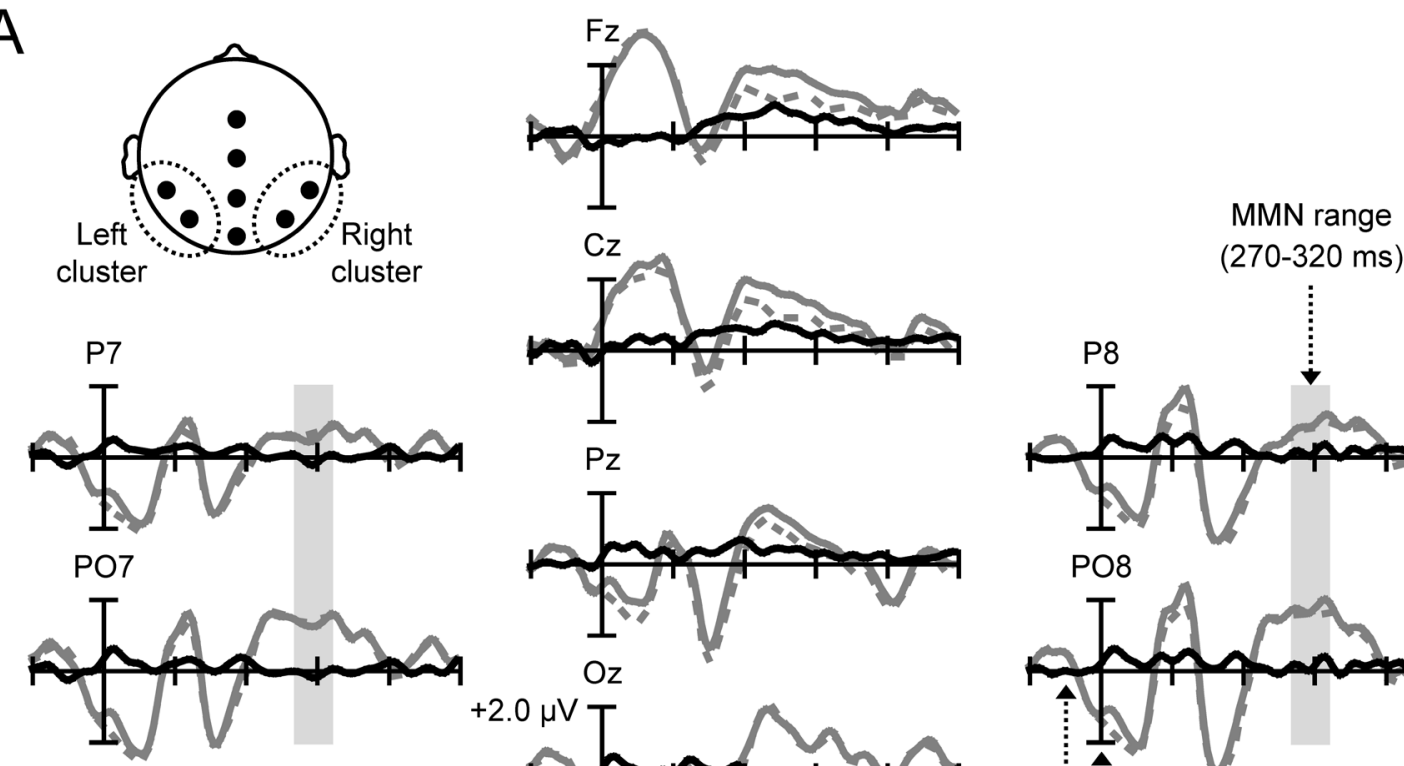

MMN range
$(270-320 \mathrm{~ms})$
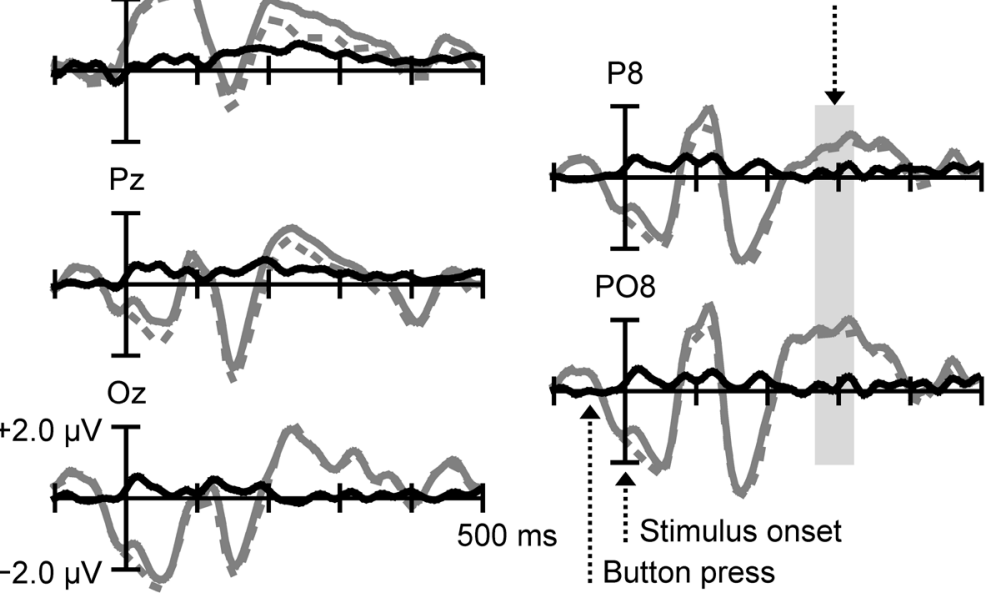

- IR(IF) " "n: R(F) — IR(IF)-minus-R(F) difference

B

MMN range (270-320 ms)
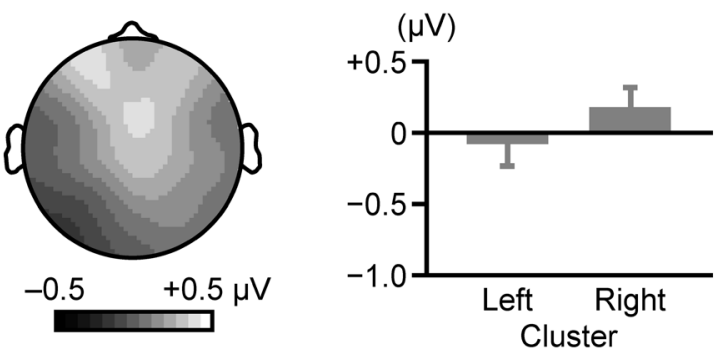

Figure 3. (A) Grand-average ERPs elicited by IR (IF) and R(F) stimuli and the IR (IF) -minus-R (F) difference wave at eight electrode locations. (B) Topographical map and mean amplitudes (left cluster from the PO7 and P7 electrodes; right cluster from the PO8 and P8 electrodes) of the IR(IF)-minus-R(F) difference wave within the 270-320 ms time window. Error bars indicate $S E$.

IR (F) -minus-R (F) and IR (IF)-minus-R (F) difference waves showed the main effect of Difference wave $\left(F(1,21)=9.50, p<.01\right.$, partial $\left.\eta^{2}=.31\right)$, revealing that the negative deflection was smaller in the IR (IF)minus- $R(F)$ difference wave than in the IR $(F)$-minus$\mathrm{R}(\mathrm{F})$ difference wave.

\section{Discussion}

Top-down control of the processing of task-irrelevant rule violation

For the primary task, the hit rate was about $90 \%$. This is comparable to those in previous visual MMN studies using a similar size-change detection task regarding a fixation point (e.g., Czigler et al., 2002, 2006; Kimura \& Takeda, 2013, in press). For the secondary task, the participants' button presses were 
fairly accurate, and the percentage of correct button presses and the mean time intervals were not significantly different between frequently-performed and infrequently-performed button presses. This pattern of results is highly similar to that found in our previous study (Kimura \& Takeda, 2014).

Compared to $\mathrm{R}(\mathrm{F})$ stimuli, IR (F) stimuli elicited an occipito-temporal negative deflection within the 270-320 ms time window. The latency and scalp topography are highly consistent with those of visual MMN observed for irregular stimuli in a complex stimulus sequence (Czigler et al., 2006; Kimura \& Takeda, in press; Stefanics et al., 2011). In contrast, physically the same IR (IF) stimuli elicited no comparable negative deflection. This means that visual MMN was elicited by rule-violating events triggered by frequently-performed button presses, but no visual MMN was elicited by rule-violating events triggered by infrequently-performed button presses. Therefore, the present result extends our previous finding (Kimura \& Takeda, 2014) and suggests that top-down control modulates the processing of ruleviolating events, even when the rule-violating events are embedded in a task-irrelevant stimulus sequence and the participants are instructed to not direct attention to the stimulus sequence. As mentioned in the Introduction, the functional role of the processing indexed by visual MMN is considered to achieve the effective selection of biologically significant visual events, even when they are unrelated to the ongoing task. From this viewpoint, this top-down modulation would be implemented to cancel out non-significant rule violation (such as self-generated rule violation) that carries no new information and facilitate the effective selection of significant rule violation (externally-generated rule violation) that can carry new information, regardless of whether the rule violation is embedded in a task-relevant or -irrelevant stimulus sequence.

The present results showed that action-induced modulation of visual MMN can be observed even when the rule violation is embedded in a task- irrelevant stimulus sequence. However, this should not be regarded as straightforward evidence that such action-induced modulation can be observed regardless of whether the stimulus sequence is attended or unattended. According to the typical experimental procedure used in previous visual MMN studies (e.g., Czigler et al., 2002, 2006; Kimura \& Takeda, 2013, in press), the present study adopted a size-change detection task regarding a continuously-presented central fixation point as the primary task and the participants were explicitly instructed to not direct attention to the surrounding stimulus sequence. This procedure is sufficient to make the surrounding stimulus sequence task-irrelevant, but is not sufficient to ensure that the participants' attention is completely directed away from the surrounding stimulus sequence. Although there was indeed no need and no task-related benefit to direct attention to the surrounding stimulus sequence, we cannot completely rule out the possibility that attention was incidentally directed to the surrounding stimulus sequence. A definitive conclusion on this issue requires further studies in which the effects of the task load of the primary task on the action-induced modulation of visual MMN are carefully investigated (cf. Heslenfeld, 2003; Kimura \& Takeda, 2013; Kremláček et al., 2013; Pazo-Alvarez et al., 2004).

Another important issue in future studies is the type of voluntary action and the effects. In both the present study and the study by Kimura and Takeda (2014), (1) the frequently-performed and infrequentlyperformed button presses were performed using different hands and (2) the left and right button presses were regularly mapped to counterclockwise and clockwise rotation of the bars, respectively. Therefore, it is still unclear whether or not the actioninduced modulation of visual MMN can be replicated even when (1) the frequently-performed and infrequently-performed button presses are performed using different fingers of one hand (e.g., the index and middle fingers of the right hand) or (2) the mapping of the left and right button presses and the direction of 
rotation is reversed. Such investigations would be important for shedding further light on the underlying mechanisms of the action-induced modulation of visual MMN.

\section{Possible mechanisms of top-down control}

According to recent theories of visual MMN (Kimura, 2012; Kimura et al., 2011; Stefanics et al., 2014; Winkler \& Czigler, 2012), visual MMN is involved in prediction based on sequential rules inherent in a visual stimulus sequence. As mentioned in the Introduction, visual MMN has been observed in response to deviant stimuli in the oddball sequence as well as irregular stimuli in a variety of complex stimulus sequences. These findings can be explained in a unified manner by assuming stimulus-contextbased predictive processing. More precisely, (1) sequential rules embedded in the temporal context of a visual stimulus are extracted, (2) a predictive model encoding the extracted sequential rules is established, (3) predictions about the forthcoming visual event are formed based on the predictive model, and (4) representations of the current visual event and the predicted visual event are compared. When incongruence between them has been detected, visual MMN is elicited (for more details, see Kimura, 2012; Kimura et al., 2011). From this viewpoint, the present result can be regarded as evidence that the stimuluscontext-based predictive processing underlying visual MMN elicitation can be modulated by top-down control.

Voluntary action is also considered to intrinsically involve sensory prediction. According to the ideomotor and common coding theories of voluntary action control (Hommel et al., 2001; Prinz, 1997), when a certain action is frequently accompanied by a certain sensory effect, a bi-directional link between the action and effect is strengthened through associative learning mechanisms (Elsner \& Hommel, 2001, 2004; Kunde, 2001, 2003). In this principle, prediction of the sensory effect before its arrival is thought to be an integral part of voluntary action production (Cardoso-Leite et al., 2010; Roussel et al., 2013; for a review, see Waszak et al., 2012). Given the existence of stimulus-contextbased and action-based prediction, the present results could be interpreted in terms of the interactive communication between them. When an event predicted on the basis of the temporal context of a visual stimulus sequence conflicts with an event predicted on the basis of the participant's action (i.e., in the case of selfgenerated rule violation), the stimulus-context-based predictive processing would be influenced by the action-based predictive processing, even when the event produced by their action was task-irrelevant. Therefore, an important issue to be addressed in the future is to determine which of the aforementioned processing stages regarding the stimulus-contextbased prediction (i.e., the extraction of sequential rules, the establishment of a predictive model, the formation of a prediction, and the comparison of current and predicted events) is influenced by the action-based predictive processing, and to understand the fundamental principles of the interactive communication between two predictive processes.

\section{Conclusion}

The action-induced modulation of visual MMN (Kimura \& Takeda, 2014) was replicated, even for rule-violating events embedded in a task-irrelevant visual stimulus sequence. This result indicates that the processing of rule-violating events indexed by visual MMN can be affected by top-down control, regardless of the task-relevance of the visual stimulus sequence. This top-down control is thought to play an important role in facilitating the effective selection of rule violation that can carry new information.

\section{Acknowledgements}

This work was supported by a Grant-in-Aid for Scientific Research from the Japan Society for the Promotion of Science (No. 26780424) to M.K. 


\section{References}

Astikainen, P., Lillstrang, E., \& Ruusuvirta, T. (2008). Visual mismatch negativity for changes in orientation: A sensory memory-dependent response. European Journal of Neuroscience, 28, 23192324.

Brainard, D. H. (1997). The Psychophysics Toolbox. Spatial Vision, 10, 433-436.

Cardoso-Leite, P., Mamassian, P., Schütz-Bosbach, S., \& Waszak, F. (2010). A new look at sensory attenuation. Action-effect anticipation affects sensitivity, not response bias. Psychological Science, 21, 1740-1745.

Czigler, I. (2007). Visual mismatch negativity: Violation of nonattended environmental regularities. Journal of Psychophysiology, 21, 224-230.

Czigler, I., Balázs, L., \& Winkler, I. (2002). Memory-based detection of task-irrelevant visual changes. Psychophysiology, 39, 869-873.

Czigler, I., Weisz, J., \& Winkler, I. (2006). ERPs and deviance detection: Visual mismatch negativity to repeated visual stimuli. Neuroscience Letters, 401, 178-182.

Delorme, A., \& Makeig, S. (2004). EEGLAB: An open source toolbox for analysis of single-trial EEG dynamics including independent component analysis. Journal of Neuroscience Methods, 134, 9-21.

Elsner, B., \& Hommel, B. (2001). Effect anticipation and action control. Journal of Experimental Psychology: Human Perception \& Performance, 27, 229-240.

Elsner, B., \& Hommel, B. (2004). Contiguity and contingency in action-effect learning. Psychological Research, 68, 138-154.

Folk, C. L., Remington, R. W., \& Johnston, J. C. (1992). Involuntary covert orienting is contingent on attentional control settings. Journal of Experimental Psychology: Human Perception \& Performance, 18, 1030-1044.

Folk, C. L., Remington, R. W., \& Wright, J. H. (1994). The structure of attentional control: Con- tingent attentional capture by apparent motion, abrupt onset, and colour. Journal of Experimental Psychology: Human Perception \& Performance, 20, 317-329.

Heslenfeld, D. J. (2003). Visual mismatch negativity. In J. Polich (Ed.), Detection of change: Event-related potential and fMRI findings. Boston: Kluwer Academic Publishers. pp. 41-60.

Hommel, B., Müsseler, J., Aschersleben, G., \& Prinz, W. (2001). The theory of event coding (TEC): A framework for perception and action planning. Behavioral and Brain Sciences, 24, 849-937.

Kimura, M. (2012). Visual mismatch negativity and unintentional temporal-context-based prediction in vision. International Journal of Psychophysiology, 83, 144-155.

Kimura, M., Katayama, J., Ohira, H., \& Schröger, E. (2009). Visual mismatch negativity: New evidence from the equiprobable paradigm. Psychophysiology, 46, 402-409.

Kimura, M., Schröger, E., \& Czigler, I. (2011). Visual mismatch negativity and its importance in visual cognitive sciences. NeuroReport, 22, 669-673.

Kimura, M., \& Takeda, Y. (2013). Task difficulty affects the predictive process indexed by visual mismatch negativity. Frontiers in Human Neuroscience, 5, doi: 10.3389/fnhum.2013.00267.

Kimura, M., \& Takeda, Y. (2014). Voluntary action modulates the brain response to rule-violating events indexed by visual mismatch negativity. Neuropsychologia, 65, 63-73.

Kimura, M., \& Takeda, Y. (in press). Automatic prediction regarding the next state of a visual object: Electrophysiological indicators of prediction match and mismatch. Brain Research.

Kremláček, J., Kuba, M., Kubová, Z., Langrová, J., Szanyi, J., Vít, F., \& Bednár̆, M. (2013). Visual mismatch negativity in the dorsal stream is independent of concurrent visual task difficulty. Frontiers in Human Neuroscience, 7, doi: 10.3389/ fnhum.2013.00411.

Kunde, W. (2001). Response-effect compatibility in 
manual choice reaction tasks. Journal of Experimental Psychology: Human Perception \& Performance, 27, 387-394.

Kunde, W. (2003). Temporal response-effect compatibility. Psychological Research, 67, 153-159.

Näätänen, R. (1992). Attention and brain function. Hillsdale, NJ: Lawrence Erlbaum.

Pazo-Alvarez, P., Amenedo, E., \& Cadaveira, F. (2004). Automatic detection of motion direction changes in the human brain. European Journal of Neuroscience, 19, 1978-1986.

Pelli, D. G. (1997). The VideoToolbox software for visual psychophysics: Transforming numbers into movies. Spatial Vision, 10, 437-442.

Prinz, W. (1997). Perception and Action planning. European Journal of Cognitive Psychology, 9, 129154.

Roussel, C., Hughes, G., \& Waszak, F. (2013). A preactivation account of sensory attenuation. Neuropsychologia, 51, 922-929.

Schröger, E. (1997). On the detection of auditory deviants: A pre-attentive activation model. Psychophysiology, 34, 245-257.

Stefanics, G., Kimura, M., \& Czigler, I. (2011). Visual mismatch negativity reveals automatic detection of sequential regularity violation. Frontiers in Human Neuroscience, 5, doi: 10.3389/fnhum. 2011.00046.

Stefanics, G., Kremláček, J., \& Czigler, I. (2014). Visual mismatch negativity: A predictive coding view. Frontiers in Human Neuroscience, 8, doi: 10.3389/fnhum.2014.00666.

Theeuwes, J. (1991). Cross-dimensional perceptual selectivity. Perception \& Psychophysics, 50, 184193.

Theeuwes, J. (1992). Perceptual selectivity for colour and form. Perception \& Psychophysics, 51, 599606.

Waszak, F., Cardoso-Leite, P., \& Hughes, G. (2012). Action effect anticipation: Neurophysiological basis and functional consequences. Neuroscience and Biobehavioral Reviews, 36, 943-959.

Winkler, I., \& Czigler, I. (2012). Evidence from auditory and visual event-related potential (ERP) studies of deviance detection (MMN and vMMN) linking predictive coding theories and perceptual object representations. International Journal of Psychophysiology, 83, 132-143.

Yantis, S., \& Jonides, J. (1984). Abrupt visual onsets and selective attention: Evidence from visual search. Journal of Experimental Psychology: Human Perception \& Performance, 10, 601-621. 